\title{
Análise da Relação Entre Produção Agroecológica, Resiliência e Reprodução Social da Agricultura Familiar no Sertão do Araripe ${ }^{1}$
}

\author{
Cecilia Tayse Muniz Teixeira² e Maria Luiza Lins Silva Pires ${ }^{3}$
}

Chegando o tempo do inverno, tudo é amoroso e terno, sentindo o Pai Eterno sua bondade sem fim. O nosso sertão amado, estrumicado pelado, fica logo transformado no mais bonito jardim (Patativa do Assaré. A festa da Natureza).

Resumo: Este trabalho analisa os sistemas de produção de base agroecológica familiar frente à situação de estiagem prolongada, considerando a sua capacidade de promover resiliência como requisito essencial para a manutenção do sistema produtivo e para a reprodução social da agricultura familiar. A questão da segurança alimentar, tomando como referência a capacidade de armazenamento e de diversificação da produção nos sistemas agroecológicos, também constitui fonte de interesse dessa pesquisa. Para isso, estabeleceu-se, como referência empírica, a análise de dois sistemas agroflorestais, um quintal produtivo e um roçado agroecológico, situados no território do sertão do Araripe e assessorados pelo Caatinga. Os casos foram ilustrativos para a compreensão da importância da assessoria técnica em bases agroecológicas para amenizar os impactos da região semiárida sobre quem nela vive e trabalha. $\mathrm{O}$ armazenamento de água, sementes e forragens, a diversificação da produção, o acesso a uma dieta balanceada e a ampliação dos canais de comercialização vêm favorecendo a reprodução social da agricultura familiar dentro do que se discute como política de convivência com o semiárido. Esse debate ganha particular relevância num momento em que o semiárido nordestino vivencia a maior estiagem dos últimos 40 anos.

Palavras-chaves: Agroecologia, assessoria técnica, resiliência e semiárido.

Abstract: This work analyzes the agroecological production in familiar front systems to prolonged drought situation, considering its ability to promote resilience as an essential requirement to maintain the productive system and the social reproduction of family farming. The issue of food security, with reference to the storage capacity and diversification

DOI - http://dx.doi.org/10.1590/1234-56781806-94790550103

1. Data de submissão: 15 de agosto de 2015. Data de aceite: 6 de setembro de 2016.

2. Universidade Federal de Santa Maria (UFSM). E-mail: taysemuniz@hotmail.com

3. Universidade Federal Rural de Pernambuco (UFRPE). E-mail: marialuizapires@gmail.com 
of production in agroecological systems is also a source of interest for this research. Selecting as empirical reference the analysis of multiple case studies, this study examined two agroforestry systems, a productive backyard garden and an agroecological swidden, located in the hinterland of Araripe territory and advised by Caatinga. The cases were illustrative to understand the importance of technical assistance in agroecological bases to mitigate the impacts of the semi-arid region of those who live and work there. The cases were also illustrative to show that the storage of water, seeds and fodder, the diversification of production, the access to a balanced diet and the expansion of sales channels have helped the social reproduction of family farming in the context of what is discussed as coexistence policy with the semi-arid region. This debate becomes particularly relevant at a time when the northeastern semiarid region experiences the longest drought in 40 years.

Key-words: Agroecology, technical advice, resilience and semi-arid region.

Classificação JEL: E26, J43, J48, L31.

\section{Introdução}

Este trabalho analisa os sistemas agroecológicos frente à situação de estiagem prolongada, por meio da análise dos aspectos relacionados aos processos de produção, distribuição e consumo de agricultores familiares no território do sertão do Araripe. Pretende-se, basicamente, destacar o aspecto relacionado à capacidade de resiliência nesses sistemas, após períodos prolongados de estiagem, identificando, particularmente, a capacidade de armazenamento da produção; alimentos para consumo e comercialização, forragem, sementes, além de outros aspectos nos sistemas de produção agroecológicas de famílias agricultoras assessoradas pelo Centro de Assessoria e Apoio aos Trabalhadores e Instituições Não Governamentais Alternativas (Caatinga). O que, em última instância, implica em analisar os fatores que contribuem para a reprodução social da agricultura familiar dentro do que se discute como política de convivência com o semiárido.

O Caatinga, ao longo dos últimos 26 anos, tem desenvolvido metodologias participativas de construção de sistemas agroecológicos junto a agricultores familiares no sertão do Araripe. No âmbito dos trabalhos desta instituição, destaca-se a parceria com o Projeto Dom Helder Camara (PDHC), cujo propósito é o de criar referências que orientem as ações de políticas públicas de combate à pobreza e promover o desenvolvi- mento sustentável. Este projeto caracteriza-se como um programa de ações voltadas ao fortalecimento dos projetos de reforma agrária e da agricultura familiar na região do semiárido nordestino, que conta com o apoio financeiro do Ministério do Desenvolvimento Agrário e do Fundo Internacional para o Desenvolvimento da Agricultura (Fida), das Nações Unidas. Cabe ao Ministério do Desenvolvimento Agrário (MDA), por meio da Secretaria de Desenvolvimento Territorial (SDT), a implementação e coordenação dessas ações.

As regiões semiáridas são caracterizadas pela aridez do clima, pela deficiência hídrica com imprevisibilidade das precipitações pluviométricas e pela presença de solos pobres em matéria orgânica. Vale salientar que esta região se caracteriza também pelos elevados níveis de pobreza, altos índices de analfabetismo, indicadores socioeconômicos relativamente baixos e concentrada infraestrutura hídrica, produtiva e social; situação particularmente acentuada no mundo rural. No caso do sertão do Araripe, esta situação se agrava pela presença de um polo gesseiro que é responsável por $95 \%$ da produção nacional (CAATINGA, 2013). Uma produção que está fortemente associada ao desmatamento da caatinga como forma de garantir a utilização da lenha e do carvão vegetal para a exploração da gipsita. Está, portanto, na indústria o maior consumo da produção de energia (92\%), o equivalente a 
1,1 milhão de $\mathrm{m}^{3}$ de lenha proveniente quase que exclusivamente da vegetação nativa da caatinga (ANGELOTTI, 2009; MMA, 2010).

Como resposta a esse quadro de aridez, de degradação e de pobreza, o objetivo geral do PDHC voltou-se, num primeiro momento, para ações capazes de aumentar a participação das famílias beneficiárias nos mercados locais, melhorando a gestão sustentável das suas atividades produtivas. Num segundo momento, o objetivo passou a se focar no fortalecimento dos processos locais, participativos e solidários, de construção social do desenvolvimento humano e sustentável (SIDERSKY et al., 2010).

Tomando-se como referência as ações desse programa, formulam-se, nessa pesquisa, alguns questionamentos: quais as estratégias que os agricultores familiares têm utilizado nos seus sistemas produtivos de base agroecológica para promoverem resiliência? Quais os impactos dessas estratégias na sua reprodução social? Na verdade, o que guiava essas questões era a tentativa de encontrar explicações para o fato de os agricultores permanecerem como agricultores, em situações marcadas por graves adversidades - de falta d'água, de pobreza, de ameaça alimentar e de dificuldade de acesso à terra e aos recursos públicos. O que nos levava novamente a indagar se as práticas agroecológicas estavam se constituindo como uma estratégia de resistência a essas adversidades, contribuindo para a reprodução social da agricultura familiar.

Assim, analisar os sistemas de produção de base agroecológica familiar frente à situação de estiagem prolongada, identificando a sua capacidade de promover resiliência como requisito essencial para a manutenção do sistema produtivo e para a reprodução da agricultura familiar constitui o foco central desta pesquisa. No âmbito dessa discussão, a questão da segurança alimentar, tomando-se como referência a capacidade de armazenamento e de diversificação da produção nos sistemas agroecológicos, estará também associada à qualidade de vida dos agricultores.

Interessa-nos destacar, nessa análise, a semelhança de Pietrafesa (2000), que:
"Para analisarmos qualidade de vida no meio rural, será preciso trabalhar com variáveis que deem conta de perceber a vivência do agricultor familiar com o meio ambiente, e como este pode interferir na reprodução social desse ator" (p. 204).

Para atender aos objetivos propostos, foi realizada, num primeiro momento, uma análise documental dos programas e projetos do Caatinga, bem como do planejamento do PDHC, além de uma inserção na bibliografia especializada. Em seguida, foram realizadas visitas à Caatinga com o objetivo de entrevistar os assessores técnicos e a coordenação colegiada, no intuito de situar melhor a concepção construída em torno dos sistemas de produção agroecológicos e a metodologia empregada no trabalho de assessoria prestada por essa ONG junto às famílias assistidas. Somente depois dessa fase, no transcorrer de 2014, foram realizadas as visitas às famílias agricultoras responsáveis pelos sistemas agroecológicos implementados pela assessoria do Caatinga. Todas elas eram integrantes da experiência piloto do Ministério do Desenvolvimento Agrário e do Fundo Internacional para o Desenvolvimento da Agricultura (Fida), das Nações Unidas, no âmbito Projeto Dom Helder Câmara (PDHC), executado pela ONG Caatinga. Foram selecionadas quatro famílias, totalizando um contingente de 12 pessoas vivendo nos sistemas produtivos agroecológicos, que foram assim distribuídas: uma em Ouricuri, uma em Santa Filomena e duas em Santa Cruz, as quais serão tratadas, a seguir, por nomes fictícios, associados às comunidades onde cada família reside: Agricultora Santa Fé, Agricultor Nova Esperança, Agricultor Pote e Agricultor Rodrigues. A seleção dessas famílias, como um estudo de casos múltiplos, isto é, no qual vários estudos são conduzidos simultaneamente ainda que moldados sob uma unidade específica (ALVES-MAZZOTTI, 2006), foi definida a partir das informações fornecidas pela ONG Caatinga, privilegiando aquelas famílias tidas como referências de modelos de sistemas agroecológicos. Pela natureza qualitativa da proposta, o estudo de caso favorece, segundo 
Yin (2005), uma investigação para se preservar as características holísticas e significativas dos acontecimentos da vida real, ainda que se reconheça o seu grau limitado de generalização.

Este trabalho está estruturado em três partes, além da introdução. Na primeira, são abordadas as principais características da região semiárida - lugar de vida dos sertanejos - dando particular destaque ao fenômeno das secas. Ainda neste capítulo será situado e caracterizado o sertão do Araripe, lócus de investigação desta pesquisa. A discussão sobre a capacidade de resistência das famílias estudadas e a sua importância na produção de alimentos frente a situações de estiagem será o destaque da segunda parte. Nela também será situada a construção da resiliência, como estratégia de convivência com o semiárido, bem como pontuada a sua importância para a reprodução social dos agricultores. Por último, na conclusão, são elencadas as estratégias de convivência adotadas pelos agricultores no esforço permanente de convivência com o semiárido. Destaca-se, nesse contexto, a importância da assessoria técnica no processo de formação dos agricultores na perspectiva da agroecologia.

\section{Fundamentação teórica}

\subsection{Semiárido: combate à seca ou convivência com a seca?}

As mudanças climáticas globais, especialmente no que diz respeito à inconstância das chuvas e ao aumento da temperatura, têm representado uma ameaça ao desenvolvimento dos cultivos agrícolas, pondo em xeque a segurança alimentar.

Essa situação de ameaça alimentar é particularmente sentida onde as dificuldades de cultivo são uma constante no dia a dia das famílias agricultoras, a exemplo das zonas semiáridas brasileiras. Tais zonas abrangem 969.589,4 km² (10,5\% do território nacional e $80 \%$ da região Nordeste), com população total de 21 milhões de pessoas (cerca de 13,5\% da população brasileira), repre- sentando o maior espaço semiárido do mundo, em termos de extensão e de densidade demográfica (SILVA, 2006).

A região semiárida caracteriza-se por conter períodos prolongados de estiagem, elevada temperatura e aridez sazonal, com médias pluviométricas variando entre 268 e $800 \mathrm{~mm}$ (APAC, 2014). Tais características modelam a paisagem do bioma caatinga, que, na língua indígena do tupi-guarani, quer dizer mata branca.

O sertão do Araripe, lócus de investigação desta pesquisa, integra dez municípios ${ }^{4}$, localizados no extremo-oeste de Pernambuco, e ocupa área de 12.020,30 km² do semiárido brasileiro, com população na ordem de 327.866 habitantes. Desses, $47 \%$ vivem na zona rural. Cerca de $68 \%$ da população vive abaixo da linha de pobreza, com renda per capita que não ultrapassa os R $\$ 70,00$ por pessoa/mês 5 .

O território do Sertão do Araripe conta com 28.143 estabelecimentos rurais, dos quais aproximadamente $98 \%$ são de famílias agricultoras, reafirmando a ideia de que, como sublinha Wanderley (2003), a agricultura familiar permanece como o principal ator dos espaços rurais, constituindo-se, ao mesmo tempo, como a principal fonte de ocupação e renda desses espaços. O que nos leva a admitir que a compreensão do Sertão do Araripe passa, necessariamente, pelas dinâmicas instituídas pelos agricultores familiares no seu cotidiano de vida e de trabalho.

A forte desigualdade social, expressa na forma de ocupação humana, na exploração dos seus recursos naturais - seja em áreas tradicionais ou estagnadas de plantios de sequeiro, seja em áreas de modernização intensa de plantios revelam os contrastes nos acessos à terra e à água das pessoas que ali vivem e trabalham.

Ao longo da história, essa situação estrutural de pobreza ainda se transforma em calamidade

4. O território Sertão do Araripe - PE abrange área de $12.020,30 \mathrm{~km}^{2}$ e é composto por dez municípios: Araripina, Granito, Ipubi, Ouricuri, Trindade, Bodocó, Exu, Moreilândia, Santa Cruz e Santa Filomena (BRASIL, 2013).

5. O IDH médio desses municípios é de 0,611 , enquanto que o do estado é de 0,705 . 
nos períodos prolongados de seca na região, no que Malvezzi (2007) considera "a problemática das secas". Uma problemática que revela uma antiga realidade de concentração de terras e de água jamais resolvida (SILVA, 2006), construída em cima das oportunidades desiguais (FIGUEIREDO, 2013). As chuvas, quando insuficientes ou irregulares, limitam a produção de alimentos, comprometendo a possibilidade de armazenamento de água, agravando enormemente a situação das famílias agricultoras, que ficam expostas às fragilidades e contradições da economia capitalista do semiárido (GALDINO, 2013).

Para enfrentar tal situação, o Estado Brasileiro, por meio do Departamento Nacional de Obras Contra a Seca (DNOCS), adotou, historicamente, Políticas de Combate à Seca. Para Galdino (2008), com o propósito de promover o desenvolvimento de uma região considerada inóspita, o DNOCS estimulava a importação de raças estrangeiras e sementes geneticamente modificadas, desconsiderando as vocações locais e o potencial endógeno da região.

Contrária à tal perspectiva, na busca de soluções para o enfretamento do fenômeno da estiagem, as organizações da sociedade civil que integram a Articulação Nacional do Semiárido (ASA) passaram a postular a diretriz de convivência com o semiárido. E, diferente da ideia de combate à seca, essa nova concepção considera o ambiente a partir de seus agroecossistemas e faz da agricultura familiar o seu principal protagonista.

Com efeito, a ideia de convivência com o semiárido fundamenta-se nas noções de acesso aos direitos à terra, à água, ao trabalho, na valorização dos recursos locais, no emprego de tecnologias sociais, na diversificação dos sistemas produtivos em bases agroecológicas e na formação de estoques de água, forragem, alimentos e sementes. Porém, como sublinham Baptista e Campos (2013), conviver com o semiárido vai além do emprego de "tecnologias caras ou baratas". Implica, antes de tudo, uma concepção de desenvolvimento na qual:
“O povo é (tido como) cidadão; que seca não se combate; que é possível conviver com a semiaridez; que a região é viável; que uma sociedade justa se constrói baseada em equidade de gênero, tendo as mulheres como protagonistas de seus destinos; e que é essencial o desenvolvimento de um processo de educação para a convivência com o semiárido que valorize o conhecimento construído pelo seu povo" (p. 52).

Tal perspectiva vem sendo desenvolvida por algumas ONGs no Sertão do Araripe, a exemplo da ONG Caatinga, garantindo, em muitos casos, o sucesso dessas experiências. Existem evidências de que os sistemas de base agroecológica contribuem enormemente para enfretamento da estiagem e que as práticas e manejos adotados minimizam o risco de perda total da produção (SALAZAR, 2012). O relatório da ONU (2012) reconhece que os manejos agroecológicos são mais equipados para suportar fenômenos como a seca, sendo, inclusive, capazes de aumentar a produtividade do campo.

Assim, vários são os itens envolvidos numa política pública de convivência com o semiárido, em que se destacam as práticas de armazenamento de alimentos, água, sementes e forragens para os animais; a substituição de animais de grande porte por médio e pequeno porte e o uso racional da água. Nesse conjunto de ações, a ênfase recai sobre a criação de uma agricultura familiar agroecológica, que seja capaz de estabelecer uma relação mais harmoniosa com natureza, por meio de uma educação contextualizada, passível de permitir uma geração de renda, a partir da aptidão local. Perspectiva esta que, segundo Galdino (2013), tende a garantir a resiliência, a partir de uma retroalimentação virtuosa do sistema. Num contexto, também, em que a introdução de tecnologias e a sua aplicabilidade social concorrem para a qualidade de vida da agricultura familiar e para a sua reprodução social (PIETRAFESA, 2000).

Por resiliência entende-se: “a capacidade intrínseca de um sistema produtivo em manter sua integridade no decorrer do tempo, sobretudo 
em relação a pressões externas" (HOLLING, 1996 apud MARZAL, 2007). Mais especificamente, refere-se à capacidade de recompor sistemas agrícolas quando afetados por perturbações de ordem ambiental, social ou econômica, por meio da criação de uma logística de captação e de armazenamento de água, de forragens e de sementes, como meio de garantir as atividades agrícolas e pecuárias, além da conservação da agrobiodiversidade (AS-PTA 2015).

Com efeito, a promoção de sistemas resilientes permite que, nos períodos de chuva, torne-se possível o acúmulo de recursos para o enfrentamento da estiagem, garantindo água, forragem para os animais e alimentação para a família (PERTESEN, 2012). Via de regra, as estratégias de estocagem têm gerado efeitos positivos no combate aos processos de desertificação e na adaptação às mudanças climáticas (SAOP, 2015).

A principal característica de um sistema resiliente é a sua flexibilidade e capacidade de perceber e/ou eventualmente criar opções para enfrentar situações imprevistas diante de pressões externas (BROOKFIELD, 2001). Brookfield (2001) chama, ainda, a atenção para as estratégias instituídas pelos agricultores para assegurar a sua reprodução social, como um elemento central na construção da resiliência do agroecossistema. Não sem razão, portanto, este autor destaca a importância do conhecimento local como fator indispensável para a promoção da resiliência. Eis a razão pela qual vem crescendo a adesão aos sistemas agroecológicos como a representação de outro modelo de desenvolvimento do campo, capaz de promover a soberania e segurança alimentar e nutricional (SEVILLA e SOLER 2010; NIEDERLE et al., 2013).

De fato, como indicam alguns especialistas no assunto, o resgate de sistemas tradicionais de manejo associado ao emprego de estratégias de manejo de base agroecológica pode representar um caminho viável para o aumento da produtividade, da sustentabilidade e da resiliência da produção agrícola (ALTIERI e NICHOLLS, 2009). Razão pela qual esses autores atentam para a necessidade de se olhar para os sistemas de outrora como sistemas incapazes de resistir e de enfrentar mudanças climáticas. A perspectiva de base ecológica viria, pois, atenuar essa vulnerabilidade do sistema, lançando as bases para ampliar a capacidade produtiva em situações de risco. É a partir daí, como admitem, que a perspectiva de base agroecológica deve emergir.

Tal perspectiva se fundamenta na ideia de que não basta apenas promover a substituição de insumos químicos externos (fertilizantes, adubos e agrotóxicos) por insumos orgânicos, mas de estruturar uma produtividade agrícola com o mínimo de impactos ambientais, sendo, ao mesmo tempo, capaz de reduzir a pobreza rural, por meio de uma relação mais equitativa entre os sujeitos envolvidos (ALTIERI, 2004; CAPAROAL e COSTABEBER, 2004).

Outros estudos também chamam a atenção para a vulnerabilidade em relação aos riscos climáticos, sugerindo que, diferente dos sistemas tradicionais, os sistemas agroecológicos, por garantirem a manutenção de maior nível de biodiversidade, com o emprego de múltiplas espécies e variedades que se combinam em variados arranjos no espaço e no tempo, tenderiam a diminuir a vulnerabilidade dos sistemas (ALTIERI, 2012; ALMEIDA et al., 2010; CAPORAL, 2009). A gestão dos riscos climáticos, admitem alguns, constitui uma das características centrais da sabedoria das famílias agricultoras. Isto porque, ao estruturarem o sistema de produção, costumam levar em conta seus conhecimentos sobre os padrões climáticos locais adquiridos com os anos de convivência e com a observação dos ciclos naturais (PERTESEN, 2009).

De qualquer modo, como destaca Altieri (2012), muitos agricultores têm se adaptado às mudanças climáticas, minimizando as perdas por meio do emprego de diversas estratégias, dentre elas: maior utilização de variedades genéticas locais tolerantes à seca, captação de água da chuva que permitam a criação de sistemas de produção diversificados a exemplo dos sistemas agroflorestais, como será visto adiante, nos casos analisados. 


\subsection{A parceria Caatinga/PDHC}

A parceria do Caatinga/PDHC foi criada a partir de 2004, tendo como área de atuação o Sertão do Araripe. Essa parceria pauta suas ações numa metodologia participativa, guiada pelos princípios da agroecologia. A assessoria prestada pelo Caatinga/PDHC se realiza por meio de visitas dos técnicos às famílias, de formações continuadas e visitas de intercâmbios entre os agricultores. Um desses primeiros encontros entre técnicos e famílias se deu em torno da preparação de fermentado biológico. ${ }^{6}$ Como descrito em relatório do Caatinga, o uso de fertilizantes e defensivos naturais vem permitindo que as famílias diminuam a dependência do consumo de insumos químicos externos, também servindo para proteger as plantas de forma natural, garantindo, ao mesmo tempo, a saúde dos agricultores. Essa prática permite manter o controle de pragas e doenças, favorecendo também um crescimento mais rápido das plantas, tornando-as mais resistentes (CAATINGA, 2007).

Para o Caatinga/PDHC, a assessoria técnica permanente (ATP) constitui uma metodologia de fundamental importância para o empoderamento das famílias. Isso porque, como observam os seus técnicos de campo, essa metodologia dá voz aos beneficiários das ações, exigindo a participação de cada um nos processos decisórios; processo esse, portanto, como sublinham, que se constitui como uma ferramenta essencial para quem trabalha com o PDHC. Tal constatação se identifica com a observação de Shutter (2012), quando afirma que a agroecologia faz uso altamente intensivo do conhecimento, baseado em técnicas que não são transmitidas a partir dos níveis superiores, mas desenvolvidas com base no conhecimento e experimentação das famílias agricultoras.
Um dos indicadores deste fato é que a agricultora Santa Fé, diferente do passado, como ela própria admite, tem hoje grande facilidade de se expressar em público, chegando, inclusive, a coordenar grupos de mulheres na comunidade, além de participar como integrante da diretoria da associação local. Situações semelhantes são descritas no livro A estratégia de Assessoria Técnica do Projeto Dom Helder Camara, em que muito da liderança dos participantes do PDHC é creditada ao enfoque metodológico da assessoria técnica (SIDERSKY et al., 2010).

Santa Fé, reportando-se ao início do trabalho da assessoria do Caatinga, admite que esse período coincidiu com a formação do comitê territorial do Araripe, quando passou a representar a associação da comunidade Santa fé no referido comitê.

Foi possível observar que, de modo geral, os agricultores demonstram uma prática de participação em associações diversas. O agricultor Nova Esperança e sua esposa, aqui identificada como agricultora Nova Esperança, estão também inseridos em diversas organizações sociais, a exemplo do Conselho Municipal de Desenvolvimento Rural Sustentável (CMDRS), sindicatos, associações, tendo assento também na diretoria da Associação dos Pequenos Produtores Rurais da Vila Algodões e Adjacências. O referido agricultor ainda é sócio da ONG Caatinga ${ }^{7}$, e da Associação dos Agricultores e Agricultoras Agroecológicos do Sertão do Araripe (Ecoararipe) junto aos agricultores Pote e Rodrigues.

A agricultora Nova Esperança também faz parte da diretoria do grupo de mulheres do assentamento, considerado, segundo esta, como um espaço de decisão e como uma forma de fortalecimento das mulheres na organização social do campo.
6. O fermentado é um adubo natural para ser utilizado no solo e nas plantas. É um adubo líquido que protege e fortalece as plantas, sem prejudicar a saúde dos agricultores, dos consumidores e sem causar danos ao ambiente (CAATINGA, 2007).
7. Assembleia Geral do Caatinga é composta por diretoria e sócios, acessado em: <http://www.caatinga.org.br/ giovanne-xenofonte-assume-coordenacao-geral-da-ong-caatinga/>. 


\subsection{Os modelos de sistema produtivo e o perfil das famílias estudadas}

Os quatro sistemas produtivos assessorados pelo Caatinga, objeto deste estudo, são assim caracterizados: dois sistemas agroflorestais, um quintal produtivo e um sistema de roçado consorciado. Todos eles vêm demonstrando formas alternativas de resistência capazes de favorecer a produção de alimentos frente à estiagem prolongada, como a ocorrida no período de 2011 a 2014, considerada a maior seca dos últimos 40 anos. Foi possível encontrar aspectos comuns nas quatro famílias beneficiárias da assessoria técnica Caatinga/PDHC, como se verá a seguir.

\subsubsection{A família do agricultor Nova Esperança}

O agricultor Nova Esperança, sertanejo, 38 anos, reside com sua esposa Nova Esperança, no assentamento do mesmo nome, localizado na cidade de Ouricuri. O casal tem dois filhos, com idades de 10 e 7 anos. A chegada ao assentamento resultou de uma situação de conflito de terra decorrente da inundação da propriedade dos seus pais, conhecida como sítio Várzea do Cosmos, pela Barragem dos Algodões, no início da década de 1980.

Este agricultor recorda que, aos 14 anos, quando estudante da escola rural de Ouricuri (ERO), teve seus primeiros contatos com a agroecologia. Naquele tempo, iniciou as primeiras práticas agroecológicas consideradas mais simples, aprendendo técnicas de adubação da terra de forma orgânica, compostagem, fermentação biológica, além da manipulação de fitoterápicos. A $\mathrm{ERO}$, inicialmente gerida pelo Caatinga, destacava-se como a primeira escola da região a trabalhar com a utilização de elementos regionais, por meio de uma educação contextualizada (CAATINGA, 2013).

O conhecimento agroecológico foi se ampliando e se consolidando na vida da família, através dos diversos processos de formação promovidos, na sua maior parte, pela ERO e mais adiante pela assessoria técnica do Caatinga em parceria com o PDHC. Esse processo de formação e aprendizagem foi o principal responsável pela mudança do sistema produtivo - de convencional para agroflorestal - desenvolvido por Nova Esperança e sua família. Assim, como foi possível constatar, Nova Esperança, diferente de outros agricultores, já havia convivido com os princípios da agroecologia desde a sua formação escolar.

Atualmente, a família do agricultor Nova Esperança desenvolve diversas atividades produtivas numa área de 2,5 hectares, sendo as mais comuns a criação de caprinos e ovinos, o plantio de hortaliças e de fruteiras, além dos roçados de milho e feijão, que se destinam tanto ao autoconsumo quanto à comercialização. Além desses, Nova Esperança planta o algodão de forma consorciada e se volta para a preservação de plantas nativas da caatinga. São 18 variedades de espécies vegetais que dão suporte à apicultura, de onde vem a maior parte da renda produtiva da família. Outra importante fonte de renda vincula-se à comercialização dos produtos agrícolas, via políticas públicas, a exemplo do Programa de Aquisição de Alimentos (PAA), e via espaços de comercialização criados pelo Caatinga, como o do empório Kaeteh ${ }^{8}$.

O acesso ao fundo rotativo solidário, a partir de 2000, foi a forma encontrada para fortalecer as atividades produtivas, especialmente a apicultura, a caprinocultura e a avicultura. "O valor era pequeno, mas me ajudou bastante na aquisição de novos animais, e depois a melhorar o rebanho", comentou o agricultor. Além dessa modalidade de crédito, foram também acessados outros financiamentos por meio da Cooperativa de Crédito Rural de Economia Solidaria do Araripe (Ecosol) e do Programa Nacional de Fortalecimento da Agricultura Familiar (Pronaf).

8. Espaço de comercialização de produtos agroecológicos das famílias assessoradas pelo Caatinga, pela Chapada e PDHC (CAATINGA, 2013), acessado em: <http://www. caatinga.org.br/emporio-kaeteh-um-espaco-de-comercializacao-de-produtos-da-agricultura-familiar-agroecologica $>$. 


\subsubsection{A família do agricultor Pote}

O agricultor Pote, 48 anos, sertanejo nascido na Cidade de Ouricuri, reside na comunidade Pote, município de Santa Cruz, desde o seu nascimento. Hoje é casado com a agricultora Pote, tem três filhos com idades de 26, 22 e 11 anos. Os dois mais velhos não residem mais com a família. As terras onde vivem foram herança dos pais do agricultor, que, depois de divididas com os seus irmãos, coube-lhe uma área de 30 ha. A baixa escolaridade de Pote, que cursou apenas a primeira série do ensino fundamental, não o impediu de escrever seus pensamentos em versos. Além de poeta e agricultor, é também presidente da Associação dos Pequenos Agricultores do Sitio Pote do Município de Santa Cruz.

Pote e sua família conheceram o trabalho com a agroecologia a partir de 2006, com a chegada do Caatinga/PDHC na comunidade. Mais recentemente, passaram a trabalhar com o sistema agroflorestal. Numa área de 12 ha de preservação de plantas nativas da caatinga, Pote iniciou o cultivo de outras culturas em consórcio como: leguminosas, gramíneas, forrageiras e plantas medicinais, num total de 72 variedades de plantas, garantindo a alimentação da família e a alimentação dos animais. Menos de $20 \%$ do que é produzido fica destinado à comercialização na própria comunidade. Há, contudo, o projeto da família em ampliar os espaços de comercialização por meio das feiras agroecológicas e dos programas de governo.

\subsubsection{A família do agricultor Rodrigues}

O agricultor Rodrigues e sua esposa são naturais de Exu e, por muitos anos, depois de uma longa trajetória como meeiros e arrendatários, conseguiram, em 1986, com a ida para a comunidade Fazenda Rodrigues, município de Santa Cruz, concretizar a realização do sonho, com a aquisição de sua propriedade. Numa área de 45 ha de terras secas e degradadas pela criação intensiva de gado, terras também de plantio de monocultivo de capim, fez-se necessário muito trabalho da família para a recuperação da terra, até o momento propício à produção de alimentos. O segundo grande investimento da família estava relacionado à construção de um barreiro com a capacidade de $10.000 \mathrm{~m}^{3}$ em 1990. Com o financiamento do Banco do Nordeste do Brasil (BNB), este reservatório passou também a abastecer, gratuitamente, cerca de 30 famílias das redondezas.

Hoje, o agricultor Rodrigues e sua esposa, mesmo aposentados, permanecem na atividade agrícola. Com exceção da produção de bananas, que é comercializada na feira local, todos os demais itens produzidos são destinados ao consumo familiar. A família tem clientela fiel, habituada a comprar bananas amadurecidas no seu tempo natural, livres, portanto, de aditivos químicos.

Rodrigues tem forte preocupação com a diversificação da produção voltada para o consumo da família. Na sua opinião, mais do que a ampliação da renda, a prioridade tem sido garantir a saúde e o bem-estar da família, ao priorizar uma alimentação saudável e diversificada. Prova disto está na manutenção de cultivos consorciados de fruteiras, hortaliças e plantas medicinais, reafirmando os estudos que associam a diversificação e integração dos sistemas ao bem-estar da família e à sustentabilidade ambiental (CAPORAL, 2009; ALTIERE, 2012).

\subsubsection{A família da agricultora Santa Fé}

A agricultora Santa Fé e seu marido residem a $30 \mathrm{~km}$ da sede do município de Santa Filomena. Dos seus sete filhos, apenas um permanece com os pais. Os demais deixaram o município pelos mais diversos motivos, embora quase sempre associados à busca de um emprego assalariado.

Esta agricultora mora na comunidade Santa Fé desde o seu nascimento. As terras onde reside e trabalha com a sua família, uma área de 14 ha, são provenientes da herança deixada pelos seus pais e que um dia já foram de seus avós. Desse montante, apenas 1,5 ha é reservado à área de produção, sendo o restante mata nativa de preservação. O casal reserva cerca de $80 \%$ da produção 
Quadro 1. Sistemas produtivos e subsistemas

\begin{tabular}{|c|c|c|c|}
\hline & $\begin{array}{l}\text { Subsistemas } \\
\text { produtivos }\end{array}$ & Espécies & $\begin{array}{l}\text { Total de } \\
\text { espécies }\end{array}$ \\
\hline \multirow{5}{*}{ 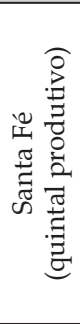 } & QUINTAL PRODUTIVO & $\begin{array}{l}\text { Goiaba, acerola, pinha, graviola, mamão, banana, maracujá, manga, cebola, coen- } \\
\text { tro, alface, couve, pimenta, beterraba, berinjela, couve, tomate, rúcula, cenoura } \\
\text { e pepino. }\end{array}$ & 20 \\
\hline & MEDICINAIS & Romã, cidreira, malva, hortelã, capim santo. & 5 \\
\hline & MATA NATIVA & $\begin{array}{l}\text { Aroeira, angico, feijão brabo, cascudo, mandacaru, palma, juazeiro, maniçoba, } \\
\text { jurema preta, imburana, favela e baraúna. }\end{array}$ & 13 \\
\hline & ROÇADO & Milho, feijão, abóbora, melancia, guandu e algodão & 6 \\
\hline & CRIAÇÃO ANIMAL & Porco e galinha. & 2 \\
\hline \multirow{5}{*}{ 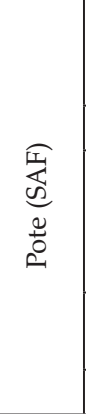 } & QUINTAL PRODUTIVO & $\begin{array}{l}\text { Mamão, goiaba, maracujá, laranja, pepino, chuchu, abóbora, melancia, jerimum, } \\
\text { coentro, alface, couve folha, tomate, couve, amora, pimentão, none, pinha, limão, } \\
\text { acerola e coco. }\end{array}$ & 21 \\
\hline & MEDICINAIS & Romã, cidreira, vick, hortelã, malva do reino, manjericão. & 7 \\
\hline & MATA NATIVA & $\begin{array}{l}\text { Imburana de cambão, imburana de cheiro, cascudo, marmeleiro, aroeira, quebra } \\
\text { faca, jurema preta, unha de gato, lambeiço, pau branco, moleque duro, mororó, } \\
\text { pau ferro, baraúna, catingueira, mandacaru, rabo de raposa, chique-chique, coroa } \\
\text { de frade, Jericó, quixaba, icó, feijão brabo, favela, alecrim e maniçoba. }\end{array}$ & 27 \\
\hline & ROÇADO & $\begin{array}{l}\text { Milho, feijão, e mamona, mandioca, macaxeira, algodão, gergelim, fava e guandu } \\
\text { e capim. }\end{array}$ & 9 \\
\hline & CRIAÇÃO ANIMAL & Gado, bode, ovelha e galinha. & 4 \\
\hline \multirow{4}{*}{ 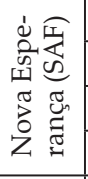 } & QUINTAL PRODUTIVO & Coentro, pimentão, quiabo, couve, e alface, mamão, pinha, acerola e batata doce. & 6 \\
\hline & FORRAGEM & Palma, grilicidia, leucina, capim nativo e sorgo, marmeleiro, melancia forrageira. & 5 \\
\hline & ROÇADO & Milho, feijão, algodão, guandu, fava e macaxeira. & \\
\hline & CRIAÇÃO ANIMAL & Gado, bode e galinha. & 3 \\
\hline \multirow{5}{*}{ 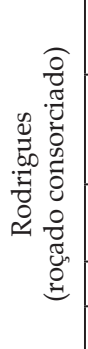 } & VAZANTE & $\begin{array}{l}\text { Mamão, cana, banana, fava, guandu, berinjela, pimentão, pimenta de cheiro, } \\
\text { batata doce, macaxeira, coentro, cebola, cebolinha, pepino e arroz. }\end{array}$ & \\
\hline & MATA NATIVA & $\begin{array}{l}\text { Imburana de cambão, imburana de cheiro, aroeira, baraúna, jurema preta, quebra } \\
\text { faca, marmeleiro, catingueira, frei jorge, angico, cascudo, maria preta, maniçoba, } \\
\text { moleque duro, batata de purga e mororó. }\end{array}$ & 16 \\
\hline & QUINTAL PRODUTIVO & $\begin{array}{l}\text { Alface, pimenta de cheiro, tomate, cenoura, beterraba, coentro, pimenta mala- } \\
\text { gueta, pimenta de cheiro, jerimum, abóbora, melão, berinjela e limão. }\end{array}$ & \\
\hline & ROÇADO & Milho, feijão, sorgo, fava, algodão, gergelim e capim & 7 \\
\hline & CRIAÇÃO ANIMAL & Ovelha, cabra, galinha e porco. & 4 \\
\hline
\end{tabular}

Fonte: Elaborado pelos autores.

para o consumo e os $20 \%$ restantes para a comercialização em feiras agroecológicas e na comunidade. Nesta última, a comercialização é realizada por meio do uso de uma bicicleta adquirida pelo projeto Novas Rendas Sertanejas ${ }^{9}$, que anuncia as mercadorias de porta em porta.

O conhecimento de Santa Fé sobre agroecologia se iniciou a partir do incentivo de sua filha mais velha que, desde 2004, já partici-

9. Novas Rendas Sertanejas é um projeto de geração de renda e oportunidade de trabalho, cuja temática é a melhoria da comercialização de produtos agroecológicos da agricultura familiar no semiárido (CAATINGA, 2012) pava do Núcleo de Educadores Populares do Sertão de Pernambuco (Nepes). A agricultora passou, então, a participar dos encontros do Nepes e do Sindicato dos Trabalhadores Rurais (STR), permitindo que Santa Fé tomasse conhecimento de outras formas de produção e de comercialização.

Santa Fé também começou a seguir as diretrizes de preservação e diversificação do seu sistema produtivo, desde o momento que passou a distribuir quase 70 espécies vegetais, dentre as nativas, forrageiras, frutíferas, hortaliças e medicinais na sua propriedade. 


\section{Resultado e discussão: as estratégias adotadas pelas famílias}

No semiárido nordestino, os sistemas de produção de base agroecológica buscam estabelecer formas de produção e de consumo capazes de melhor enfrentar os períodos de estiagem prolongados, através da diversificação de produtos, da ampliação da oferta de alimentos e da independência de insumos externos (CAATINGA, 2012).

Há, nas falas das famílias, uma valorização da assessoria técnica, pela oportunidade que é oferecida de formação, intercâmbios e planejamentos, permitindo o aprimoramento do conhecimento sobre suas práticas agrícolas.

"Quando o técnico começa a assessorar, per-
mite um acompanhamento mais preciso. Eles
sistematizam, começam a desenvolver um tra-
balho em parceria até com outras organizações
e outras comunidades. O técnico traz inter-
câmbio, vindo outras famílias visitar e a gente
também sai" (Agricultor Nova Esperança).

Algumas ações de convivência com o semiárido são particularmente destacadas no processo de assessoria prestada pela Caatinga/PDHC, a exemplo da estratégia da estocagem, da diversificação e integração dos subsistemas, da preservação do bioma da caatinga e do uso dos defensivos naturais.

\subsection{As estratégias de convivência do semiárido adotadas pelas famílias}

\subsubsection{A estratégia da estocagem}

As estratégias de convivência com o semiárido movem as ações da assessoria técnica do Caatinga/PDHC. Por meio dessa assessoria, as quatro famílias estudadas puderam ter acesso à tecnologia social de captação de água de chuva para o consumo, melhorando a produtividade dos cultivos. A importância dessa tecnologia foi assim expressa pela agricultora Santa Fé: "a cisterna foi uma das melhores coisas que já fomos beneficiados, pois com água e economizando, tudo é possível".

Para Siliprandi (2005), os bons resultados da produção de alimentos de base agroecológica se devem, em grande medida, ao apoio das tecnologias sociais de acesso à água, construídas de forma participativa com os próprios agricultores/ as, ONGs e algumas organizações locais, o que tende, na sua opinião, a favorecer a promoção da soberania e segurança alimentar e nutricional.

A agricultora Santa Fé e o agricultor Pote relatam que, com as tecnologias sociais, aprenderam a economizar água, especialmente nos meses mais escassos de chuva, desenvolvendo a prática de cobertura morta nas plantas, utilizando folhas, galhos e restos de vegetais para proteger a água do fenômeno da evaporação, além de outras medidas. Com o apoio da tecnologia da cisterna calçadão, o agricultor Pote cultivou, na última estiagem de 2012, 11 espécies de horticultura. Nesse mesmo período, a agricultora Santa Fé manteve a produção de nove pés de goiabeiras, aguando-as a cada oito dias, no âmbito das exigências da prática de cobertura morta.

A ASA (2012) identifica essas estratégias de armazenamento de água como ações estruturadoras para a manutenção da produção de alimentos em períodos de estiagem, as quais são destacadas por Altieri (2012) como sendo capazes de amenizar perdas e de permitir a adaptação da convivência com o clima semiárido. $\mathrm{O}$ agricultor Nova Esperança, embora reconheça a importância das tecnologias de armazenamento de água na manutenção do seu sistema agroflorestal, admite que tais tecnologias ainda não são suficientes para garantir a produção o ano todo, alegando precisar contar com o apoio das políticas emergenciais do governo, como do popular carro-pipa.

O armazenamento das sementes crioulas destaca-se, também, como uma prática importante de convívio com o semiárido. Esse procedimento gera mais autonomia ao agricultor, na medida em que lhe permite plantar no tempo que lhe convém, com a vantagem ainda de apresentar igual ou maior resistência quando com- 
paradas às sementes transgênicas (ASA, 2014). A importância da prática da estocagem de sementes é reconhecida por Morais et al., (2009) como essencial para a reprodução das famílias, por garantir uma estabilidade de oferta de alimentos para o consumo familiar e forragens para os animais nos períodos secos, estabilizando a oferta de alimentos durante todo o ano.

O exemplo do agricultor Nova Esperança é ilustrativo a esse respeito. Ele faz silo para armazenar milho e sorgo e prepara feno da palha do feijão, da palha de milho e de capins nativos e cultivados. Guarda, ainda, o milho e o sorgo em grãos que, durante a seca, será triturado e fornecido aos animais, junto com o silo e o feno. A prática de estocagem desse agricultor permite que a família aumente o seu criatório, diminuindo, ao mesmo tempo, as perdas com a mortalidade dos animais.

O agricultor Nova Esperança admite que, nos anos de estiagem, foi forçado a reduzir enormemente a quantidade de sementes guardadas. Por conta disso, ele não poupa esforços em adquirir as sementes crioulas de outros agricultores, chegando, inclusive, a procurá-las em comunidades mais longínquas, mesmo considerando a existência, ainda que precária, de um banco de sementes comunitário no assentamento onde reside. $\mathrm{O}$ agricultor Rodrigues também externa forte preocupação em torno das sementes crioulas. Detentor de um estoque de 18 variedades dessas sementes, chega a se autointitular como um "guardião das sementes". No caso da agricultora Santa Fé, o armazenamento de sementes crioulas se dá de forma coletiva, por meio de um banco comunitário que envolve 11 famílias. Com efeito, a estocagem de todos os recursos, como sementes, água, forragens e alimentos, proporciona às famílias agricultoras diversas alternativas para atravessar o período seco, sem que tenham que abandonar sua propriedade, recorrendo à migração (CARVALHO, 2012).

Há, ainda, duas outras tecnologias sociais acessadas pelas quatro famílias que são tidas pela assessoria técnica do Caatinga/PDHC como importantes estratégias de conivência com o semiárido. São elas: os fogões agroecológicos e o bioágua. Todos os sistemas adotados são responsáveis pela redução do consumo de lenha e conservação do bioma da caatinga e pela reutilização de águas domiciliares na produção de canteiros de hortas e fruteiras, respectivamente.

Seja como for, as estratégias que buscam melhor convivência com o semiárido, a exemplo das praticadas das pelas quatro famílias estudadas, tendem a aumentar a resiliência ecológica dos sistemas de produção, tornando-se essenciais, ainda que não suficientes, para alcançar a sustentabilidade da atividade produtiva (ALTIERI, 2012).

\subsubsection{A diversificação e integração dos subsistemas}

As culturas habitualmente cultivadas antes da assessoria prestada pelo Caatinga/PDHC, como milho e feijão ou monocultivos de capim, eram responsáveis, quase sempre, pela ausência de cobertura da vegetação nos solos durante os nove meses. Solos expostos a altas temperaturas e a sua consequente degradação eram algumas das consequências observadas.

Aliava-se a isso o hábito de vender o esterco dos animais, ao invés de utilizá-lo como adubo orgânico no solo, comprometendo a manutenção de solos saudáveis, com boa atividade biológica, o que, por conseguinte, também concorria para comprometer a resiliência dos sistemas agrícolas (ALTIERI, 2012).

O que se observou no caso das famílias estudadas, é que essas antigas práticas pautadas no monocultivo e na venda de adubo orgânico foram sendo, aos poucos, substituídas, graças ao apoio da assessoria técnica de base agroecológica oferecida pelo Caatinga/PDHC. Simultaneamente, crescia, por parte dos agricultores, a adoção de técnicas relacionadas à cobertura morta, à adubação orgânica à base de esterco de animais, o plantio consorciado, entre outras práticas, que, paulatinamente, modificavam aquela árida paisagem rural. Como admitido pelo agricultor Pote, a paisagem da área em que trabalhava antes da adoção de manejos de base agroecológica era "um deserto, tudo limpo, por perto só os 
roçados de milho feijão e mamona e monocultivo de pastos para animais. Agora é tudo muito diferente", sublinha. Situação semelhante fora vivenciada por Santa Fé, ao admitir que, numa área antes sem qualquer cultivo, tornou-se, num período de cinco anos, com a utilização de "garranchos, folhas e pau secos, restos de culturas, esterco bovino", a área mais produtiva do local. Hoje, esta agricultora se alegra ao comentar sobre a diversidade de plantios contida no seu sistema produtivo, que engloba 14 tipos de fruteiras e 11 culturas diferentes de hortaliças, substituindo, assim, o monocultivo de pasto, anteriormente existente.

A estratégia de diversificação da produção alcança ganhos ambientais expressivos, na medida em que agrega grandes quantidades de matérias orgânicas em seus solos, aumentando também a capacidade hídrica (ALTIERE, 2012). Alia-se a isso a melhoria da alimentação que tal diversificação permite. Esse foi um dado, inclusive, destacado pelo agricultor Nova Esperança, ao se referir às mudanças relacionadas à adoção da diversificação da sua produção, como já sublinhado neste trabalho.

A integração das atividades produtivas também foi uma realidade observada nos casos estudados. Nos sistemas produtivos de Pote e Nova Esperança, o esterco dos animais é utilizado como adubo orgânico nos canteiros de hortaliças e a sobra da colheita das hortas é destinada ao alimento das galinhas. Já no sistema produtivo do agricultor Rodrigues, as ramas da sua produção de batatas são destinadas à alimentação dos porcos, galinhas e ovelhas, que, por sua vez, garantem a alimentação da família. Graças a esse procedimento, foi possível superar a estiagem de 2012, fugindo da necessidade de vender os animais ou de comprar ração para alimentação animal. A integração dos sistemas, na qual as atividades produtivas estão interligadas constitui, na perspectiva de Caporal e Costabeber (2004), uma possibilidade de revelar a sustentabilidade sob o ponto de vista agroecológico.

\subsubsection{A conservação do bioma da caatinga}

As práticas agroecológicas desenvolvidas pelas famílias contribuem para a manutenção do bioma da caatinga, especialmente por meio da conservação das culturas nativas. Como admite Gliessman (2001) a esse respeito, a preservação da diversidade biológica e cultural se constitui como um critério essencial para a integridade do sistema produtivo. $\mathrm{O}$ agricultor Pote, por exemplo, numa área de apenas 12 ha, consegue abrigar, por meio do sistema agroflorestal, 31 espécies de plantas nativas junto com o plantio de roçado. ${ }^{10}$ Situação semelhante é também encontrada com Nova Esperança, para quem a permanente preocupação com a devastação ambiental se constituiu como a principal motivação para a adoção do sistema agroflorestal. Esses agricultores reconhecem o papel que exercem junto a outras famílias do entorno, multiplicando a ideia de que é possível produzir alimentos preservando o bioma, sem a necessidade de desmatamentos e usos de queimadas. Todos os agricultores relataram que a maior parte da ração dos animais é produzida dessas culturas nativas em forma de feno e atribuem a baixa incidência de doenças dos caprinos e ovinos a esse tipo de manejo.

Segundo Altieri (2012), o emprego de uma maior utilização de variedades genéticas locais garante maior estabilidade e menor perda de produtividade durante a seca, tendo em vista que as plantas nativas apresentam maior resistência nesse período de estiagem. Além disso, a importância da conservação do bioma da caatinga está em permitir a recuperação de área já degradada, contribuindo para a regeneração natural e a sucessão de espécies (FAVERO et al., 2008).

Como foi possível observar, os agricultores estudados organizam suas atividades produtivas de forma diversificada e integrada por atender, na

10. Dentre as mais comuns estão a imburana, aroeira, braúna, jurema preta, quebra faca, marmeleiro, catingueira, juá, cascudo, freijó, mororo, maria preta, moleque duro, feijão brabo. 
concepção de Gliessman (1990), a três critérios principais: o primeiro relacionado à baixa dependência de insumos externos, pois, com a doação dos defensivos naturais, os agricultores utilizam as plantas do próprio sistema, permitindo que a alimentação dos animais seja de plantas da caatinga preservada. O segundo critério está relacionado à aceitação e/ ou tolerância das condições locais, por meio de manejos como cobertura morta, adubo dos solos, armazenamento de água. A adoção desses manejos permitiu que as quatro famílias se adaptassem às condições ambientais do sertão, mantendo-as produzindo, mesmo nos períodos de estiagem. E, finalmente, o terceiro critério está relacionado à manutenção, a longo prazo, da capacidade produtiva, tendo em vista a prática do armazenamento de sementes, água e forragem para os animais.

Todas essas atividades são identificadas como estratégias de convivência com o semiárido, sendo consideradas pela equipe técnica do Caatinga/PDHC como de fundamental importância na preparação dos agricultores para os períodos de estiagem.

\subsubsection{O uso dos defensivos naturais}

Todos os agricultores estudados utilizam tão somente os defensivos naturais para a proteção de suas lavouras. O agricultor Rodrigues, por exemplo, costuma utilizar o fermentado biológico na produção de hortaliças e feijão e, menos frequentemente, nas culturas de roçados consorciadas (mamona, feijão, fava, milho).

Outras práticas de base agroecológica adotadas, também destacadas pelos agricultores Pote e Rodrigues, foram disseminadas durante as formações continuadas sobre o uso de defensivos naturais. Destacam-se os defensivos à base de alho, de extrato de $\mathrm{Nim}^{11}$, de folhas de pinha e de

11. Árvore de grande porte, pertencente à família do mogno e do cedro. Nativa do subcontinente indiano, é conhecida por suas propriedades medicinais encontradas nas sementes, folhas e casca e popularmente utilizada na agricultura, no combate a lagartas e pragas, como nematoides, fungos e bactérias (Disponível em: < http://pt.wikipedia. org/wiki/Neem>, acesso em outubro de 2014). folhas de pimenta malagueta, possibilitando produção limpa, livre de produtos químicos e com menos incidência de pragas e insetos nas culturas cultivadas.

Os agricultores Nova Esperança, Rodrigues e Santa Fé ainda fazem fitoterápicos para o tratamentos dos animais, produzindo calda da casca de angico como cicatrizante e batata de purga e melancia de cavalo como vermífugo.

Na concepção dos agricultores, a importância da adoção dessas práticas estava particularmente associada ao fato de não comprometerem a saúde, como no tempo em que trabalhavam aplicando agrotóxicos, como relatado pelo agricultor Rodrigues. Com isso, dores de cabeça, tonturas e enjoos deixaram de fazer parte do seu dia a dia. A importância também estava atribuída à possibilidade de diversificação do sistema produtivo, ampliando a oferta de alimentos para a família e para a comercialização.

Os casos aqui relatados exemplificam as estratégias utilizadas pelos agricultores - de hortas e pomares, além da criação de animais de pequeno porte e de produção de mel de abelhas - dentro dos preceitos da agroecologia, ressaltando, em todos eles, a relação entre produção e autoconsumo. Como admitem Grisa e Schneider (2008), nesse sentido, a produção para o autoconsumo constitui uma forma de organização da vida social que reflete a sociabilidade, identidade e um "repertório" cultural entre os agricultores. Esses autores admitem ainda que tal produção, também conhecida como consumo doméstico ou "produção para o gasto", associa-se a outras estratégias habitualmente utilizadas pelos agricultores como a pluriatividade, o acesso aos benefícios da previdência social e participação em redes de reciprocidade, compondo um elenco necessário para a sua reprodução social. Finalmente, os casos aqui relatados também sinalizam as possibilidades contidas na relação estabelecida entre agricultor familiar e meio ambiente na reprodução social dos agricultores. 


\section{Conclusão}

Este trabalho se propôs a estudar os sistemas agroecológicos frente à situação de estiagem prolongada, por meio da análise dos aspectos relacionados aos processos de produção, distribuição e consumo de agricultores familiares. Para tanto, fez-se necessário compreender o processo de assessoria técnica desenvolvido pelo Caatinga/ PDHC junto às famílias agricultoras no território do sertão do Araripe.

Com efeito, num contexto de semiaridez, esse processo de assessoria técnica se pautou em ações capazes de amenizar os impactos das mudanças climáticas, especialmente em ocasiões de estiagem prolongada, a exemplo do que se iniciou em 2012, na maior estiagem dos últimos 40 anos.

Os sistemas agroflorestais, o roçado agroecológico e o quintal produtivo, sob a responsabilidade das famílias agricultoras de Santa Fé, Pote, Rodrigues e Nova Esperança, foram ilustrativos para a compreensão de como se constrói uma agricultura sustentável, partindo do resgate dos saberes já existentes, aliado à assessoria técnica e à valorização dos potenciais endógenos da região.

Essas experiências alavancadas pelo Caatinga/ PDHC se pautaram na valorização dos saberes populares, tanto para garantir o armazenamento de água, sementes e forragens para os animais, como para orientar a diversificação da produção e a ampliação dos canais de comercialização no que hoje se discute como política de convivência com o semiárido.

As diversas falas dos entrevistados revelaram a importância da assessoria técnica para a alavancagem do processo de transição agroecológica. Nos casos em questão, tal assessoria veio associada à tomada de consciência das famílias sobre a importância da produção de alimentos limpos de produtos químicos e da diversificação da produção para o autoconsumo e para a comercialização. Essa tomada de consciência tornou-se, assim, essencial para que os agricultores passassem a lidar melhor com a dura realidade de falta d'água, permitindo-lhes não apenas que se afas- tassem do desejo de abandono do local, mas que passassem a valorizar esse local onde vivem e trabalham.

A diversificação da produção assegurou às famílias uma dieta mais balanceada, ampliando, também, as possibilidades de comercializar novos produtos, até então fora do elenco daqueles tradicionalmente comercializados.

Os resultados chamam a atenção para o fato de que, em todos os sistemas analisados, fez-se presente a produção de alimentos saudáveis para o autoconsumo, concorrendo para se pensar, à semelhança de outros trabalhos aqui citados, a importância da qualidade dos alimentos, da segurança e da ampliação indireta da renda familiar na reprodução social da agricultura familiar.

Assim, a importância do autoconsumo para a reprodução social dos agricultores, minimizando a vulnerabilidade alimentar das famílias e a diminuição da pobreza rural, não nos permite, à semelhança de Grisa e Schneider (2008), conceber a produção voltada ao autoconsumo como sendo algo residual e de baixa qualidade. Do mesmo modo que também não se pode desqualificar a comercialização de parte da produção, no âmbito da "complementaridade" do consumo, permitida por esse processo, como também se referem esses autores.

Os mercados locais, a exemplo das feiras agroecológicas dos municípios de Ouricuri e Santa Filomena ou até mesmo da comercialização de porta em porta, hoje já praticada pelas famílias Santa Fé e Nova Esperança, tornaram-se particularmente importantes para o escoamento da produção e para troca de experiências entre os agricultores. Mesmo assim, foi possível constatar que o fortalecimento da comercialização passa pela conquista de espaços em redes de comercialização, a exemplo do Empório Kaeté e da ampliação dos mercados já existentes.

De todo modo, com a construção desses sistemas de base agroecológica, as famílias aqui analisadas abriram um novo canal para a obtenção de renda, ao mesmo tempo em que passaram a exercer maior controle sobre todo o processo produtivo, desde a produção e o armazenamento até a comercialização. Balizadas na diversificação e no 
manejo agroecológico de culturas, de acordo com os ciclos produtivos (safra e entressafra) dos seus plantios, adequaram-se mais satisfatoriamente aos seus agroecossistemas, reafirmando os estudos de Altieri (2012), que identificam, nesses sistemas, a possibilidade de ampliar a oferta de alimentos, de elevar a renda familiar e de garantir a segurança alimentar no meio rural. Assim, o acesso a uma dieta mais balanceada e a possibilidade de ampliação dos espaços de comercialização constituem elementos importantes para a reprodução social dos agricultores em contextos de fortes adversidades climáticas, econômicas e sociais.

O que está em jogo, portanto, é o cuidado prioritário com o manejo da terra, permitindo-lhes, assim, produzir em períodos de forte estiagem, coisa inimaginável antes da adoção do sistema produtivo de base agroecológica, em que todo o plantio esteve, quase sempre, resumido ao monocultivo de capim, associado ou não ao plantio de milho e feijão. Assim, o apoio da assessoria do Caatinga/PDHC, desde 2007, foi essencial para o (re)desenho dos sistemas produtivos com as mudanças aí implicadas sobre a vida da família e sobre a dinâmica produtiva local.

Mesmo assim, um maior volume de comercialização durante todos os meses do ano ainda é um desafio para as famílias, que hoje só têm assegurado mais fortemente essa possibilidade nos períodos chuvosos. Isso significa que as tecnologias sociais, embora fundamentais para produção de alimentos frente à estiagem, nem sempre se mostraram suficientes para garantir uma produção que não se reduza à subsistência da família. Fato que ainda não permite que as famílias rompam com a dependência das políticas assistencialistas, a exemplo da operação Combate à Seca, na qual a oferta de carros-pipa vem fomentando a tão conhecida "indústria da seca" e pondo em xeque, ao mesmo tempo, o alcance da assessoria participativa das ONGs e dos resultados promissores das tecnologias sociais.

Entretanto, não se pode deixar de reconhecer que a resiliência dos sistemas agroecológicos tem sido também favorecida pelo acesso das famílias aos benefícios sociais, como bolsa estiagem, bolsa família, aposentadoria rural, garantia safra e acesso aos créditos como Pronaf e fundo Rotativo solidário. Mas, como evidencia o documento elaborado pela Articulação Nacional do Semiárido (2012), muito mais importante do que os benefícios sociais para a manutenção das famílias nos espaços rurais são os investimentos numa educação contextualizada, no acesso à terra, no acesso ao crédito, na assessoria técnica e em programas de geração de renda.

De todo modo, apesar das limitações ainda existentes, foi possível constatar que as estratégias adotadas pelas famílias estão lhes permitindo permanecer nas suas terras, ampliando as oportunidades de trabalho e renda, contribuindo, assim, para melhor qualidade de vida no sertão. O que significa afirmar, noutros termos, que essas famílias agricultoras vêm garantindo a resiliência do modelo agroecológico adotado, contribuindo para a garantia da qualidade de vida e da reprodução social da agricultura familiar. Nesse sentido, como sublinha uma agricultora: "É só se preparar. O segredo maior é armazenar, não desmatar, não queimar a terra; assim, se produz por uma vida toda", afirmou a agricultora Santa Fé.

Uma qualidade de vida, portanto, que não se apoia tão somente em relação à elevação de renda ou à introdução de procedimentos técnicos, mas que se redefine nas relações estabelecidas entre agricultores e meio ambiente, instituindo, como admite Pietrafesa (2000), uma forte dependência entre ambos na reprodução social dos agricultores.

Esta é a razão pela qual este trabalho reafirma a importância da assessoria técnica promovida pelas ONGs voltadas à produção agroecológica, bem como as trocas de experiências entre os agricultores, estimuladas por essas assessorias, como condição essencial para a reprodução do modelo agroecológico e para a reprodução da condição social do agricultor, na garantia de sua autonomia. Não sem razão, portanto, como sublinha Altieri (2012), a resiliência não estaria apenas no âmbito agroecológico, mas também na própria família, ao que ele chama de resiliência social.

A importância dos casos estudados para a compreensão da reprodução dos sistemas pro- 
dutivos e da reprodução social dos agricultores sugere a continuidade dos estudos, a partir de novos questionamentos, dentre os que se seguem: em caso de interrupção dessa assessoria técnica, as famílias já teriam autonomia para assegurar a resiliência dos seus sistemas produtivos agroecológicos? Os modelos aqui estudados têm sido capazes de tornar a agricultura atrativa para os jovens? $\mathrm{O}$ que implica, noutros termos, perguntar, os jovens darão prosseguimento a essas experiências?

Todas essas indagações se fazem necessárias para a ampliação do conhecimento nesse campo e para o aprimoramento de políticas públicas capazes de fomentar estratégias mais eficazes de convivência com o semiárido, garantindo vida boa e mesa farta para o conjunto dos agricultores que fazem de seus sistemas produtivos um local de vida e de trabalho.

O que nos leva a admitir, à semelhança de alguns estudiosos da região, que o semiárido não é apenas clima, vegetação, solo, sol ou água. "É povo, música, festa, arte, religião, política e história." É processo social. É um espaço de vida no qual as famílias, historicamente, criaram as condições de vida nesta região e encontraram, na caatinga, formas de resistência e de convivência para se reproduzirem como agricultores familiares.

\section{Referências}

ANGELOTTI, F., SÁ, I. B. e PETRERE, V. G. Mudanças climáticas e o Semiárido brasileiro: o papel da Embrapa Semiárido e suas áreas de pesquisa. Petrolina: Embrapa Semiárido, 26 p. 2009, (Série Documentos Online, 223).

ALMEIDA, E., PERTESEN, P. e PEREIRA, F. J. Comparação entre custos de produção de milho comprova vantagem da agroecologia. 2010. Disponível em: <http:// www.agroecologiaemrede.org.br/experiencias. php? experiencia $=992>$. Acesso em: 10 set. 2014.

ALTIERI, M. Agroecologia: a dinâmica produtiva da agricultura sustentável. Porto Alegre: Editora da UFRGS, 2004.

A. Agroecologia: bases cientificas para uma agricultura sustentável. 3. ed. rev. ampl. São Paulo, Rio de Janeiro: Expressão popular, AS PTA, 2012.
. e NICHOLLS, C. I. Mudanças climáticas e agricultura camponesa: impactos e respostas adaptativas. Revista agriculturas, v. 6, n. 1, abr. 2009.

ALVES-MAZZOTTI, A. J. Usos e abusos dos estudos de caso. Cadernos de Pesquisa, São Paulo, v. 36, n. 129, set./ dez. 2006, p. 637-651.

APAC - Agência Pernambucana de Águas e Clima, 2014. Disponível em: <http://www.apac.pe.gov.br/ meteorologia/estacoes-do-ano.php?estacao $=$ verao $>$. Acesso em: 12 nov. 2013

ASA. Documento da Articulação Nacional do Semiárido brasileiro, Declaração sobre o atual momento da seca no semiárido, 2012. Disponível em: <http://www.moc. org.br/download/24-05-2012_Documento\%20ASA\% 20 OFICIAL.pdf>. Acesso em: 20 jan. 2014.

Animais e plantas da Caatinga também têm suas estratégias de convivência com o Semiárido, 2014. Disponível em: <http://www.asabrasil.org.br/Portal/ Informacoes.asp?COD_NOTICIA $=8375>$. Acesso em: 23 jul. 2014.

AS-PTA. Agricultura familiar e agroecologia, 2015. Disponível em: < http://www4.planalto.gov.br/consea/ comunicacao/noticias/2015/campina-grande-pbrecebe-seminario-internacional $>$. Acesso em: 31 jan. 2015.

BAPTISTA, N. de Q.; CAMPOS, C. H. A convivência com o Semiárido e suas potencialidades. In: CONTI, I. L. e SCROEDER, E. O. (Orgs.). Convivência com o semiárido brasileiro. Autonomia e Protagonismo Social COOPERAÇÃO BRASIL - ESPANHA, Programa Cisternas - BRA 007-B, 2010 - 2014, Brasília Editora IABS, 2013, p. 51-58.

BROOKFIELD, H. Exploring agrodiversity. New York: Columbia University Press, 2001.

CAATINGA. O informativo. A seca castiga, mas não seca a fé das famílias agricultoras, n. 15, p. 2, 10 maio. 2012. Disponível em: <http://www.caatinga.org.br/ wp-content/uploads/2012/11/O-Caatinga15.pdf $>$. Acesso em: 10 fev. 2014.

CAPORAL. F. R. Agroecologia: uma nova ciência para apoiar a transição a agriculturas mais sustentáveis. Brasília, 2009. 30 p. Disponível em: <http://www. alice.cnptia.embrapa.br/alice/bitstream/doc/911596/1/ LVAgreoecologia.umacienciaparaapoiar.pdf $>$. Acesso em: 30 jun, 2014.

CAPORAL F. R. e COSTABEBER, J. A. Agroecologia: alguns conceitos e princípios. MDA/SAF/DATER-IICA, Brasília, 2004. 
CARVALHO, P. P. A convivência com o semiárido como estratégia para o combate à desertificação: uma experiência no Sertão do Araripe. Agriculturas, v. 9, n. 3, dez. 2012.

FAVERO, C., LOVO, I. C. e MENDONCA, E. S. Recuperação de área degradada com sistema agroflorestal no Vale do Rio Doce, Minas Gerais. Revista Árvore, Viçosa, v. 32, p. 861-868, 2008.

FIGUEIREDO, M. et al. (Orgs.). Estratégia agroecológica para o semiárido. In: GALDINO, W. C. M. (Org.). Vozes da convivência com o semiárido. Recife: Centro Sabiá, 2013.

GALDINO, W. C. M. Intervenção rural e autonomia: a experiência da articulação no semiárido/ASA em Pernambuco. Recife: Ed Universitária, 2008.

. (Org.). Vozes da convivência com o semiárido. Recife: Centro Sabiá, 2013.

GLIESSMAN, S. R. Agroecologia: processos ecológicos em agricultura sustentável. 2. ed. Porto Alegre: Ed. Universidade/UFRGS, 2001. 653 p.

GLIESMAN, S. R. e GLIESSMAN, S. R. Quantifyng the agroecological component of sustainable agriculture: a goal. In: GLIESSMAN, S. R. (Ed.). Agroecology: researching the ecological basis for sustainable agriculture. New York: Springer-Verlag, 1990.

GRISA, C. e SCHNEIDER, S. "Plantar pro gasto": a importância do autoconsumo entre famílias de agricultores do Rio Grande do Sul. RER, Piracicaba, SP, v. 46, n. 02, p. 481-515, abr.juun. 2008.

MALVEZZI, R. O Semiárido: uma visão holística. Brasília: CONFEA, 2007.

MARZALL, K. Agrobiodiversidade e resiliência de agroecossistemas: bases para segurança ambiental. Revista Brasileira de Agroecologia, v. 2, n. 1, Guarapari, ES, 2 fev. 2007.

MMA - Ministério do Meio Ambiente. Relatório do Workshop sobre Cenários Climáticos do Semiárido e Implicações para o Desenvolvimento do Nordeste. Fortaleza, 2010. Disponível em: <http://www. iicabr.iica.org.br/wp-content/uploads/2014/03/ Mudan\%C3\%A7asClim\%C3\%A1ticas.pdf>. Acesso em: 10 jul. 2015.

MORAIS, C. M., CARVALHO, P. P. e SOUZA, J. E. Respostas às mudanças climáticas percepção e reações frente às mudanças climáticas no semiárido brasileiro. Revista Agriculturas, v. 6, n. 1, Rio de Janeiro, AS-PTA, 2009.

NIEDERLE, P. A., ALEMIDA, L. e VEZZANI, F. M. (Orgs.). Agroecologia: práticas, mercados e políticas para uma nova agricultura. Curitiba, PR: Editora Eletrônica, 2013.
ONU. Fao no Brasil memória de cooperação técnica, 2012. Disponível em: <https://www.fao.org.br/download/ LivroFAOBrasilMemoriaCooperacaoTecnica.pdf $>$. Acesso em: 10 jan. 2015.

PERTESEN, P. Muitas frutas, mas também muitos problemas. Revista Agriculturas: experiências em agroecologia, v. 6, n. 3, Rio de Janeiro, AS_PTA, out. 2009, p. 22-25.

. Agroecologia para convivência com o semiárido, 2012. Disponível em: < http://www.agroecologia.org.br/index. php/noticias/317-agroecologia-para-convivencia-como-semiarido >. Acesso em: 20 set. 2013.

PIETRAFESA, J. P. Agricultura familiar e reprodução social. Sociedade e Cultura, Goiânia, v. 3, n. 1 e 2, jan./ dez. 2000, p. 185-216.

SALZAR, A. H. Proposta metodológica de medição de resiliência agroecológica em sistemas sócio-ecológicos: um estudo de caso nos Andes Colombiano. Dissertação (Mestrado) - Universidade Federal de São Carlos, 2012.

SASOPE. Seminário Internacional de construção de Resiliência em regiōes semiáridas. 2015, Disponível em: $<$ http://www.sasop.org.br/noticia.php?cod=131>. Acesso em: 30 jan. 2015

SEVILLA, G. e SOLER M. M. Agroecología y soberanía alimentaria: alternativas a la globalización agroalimentaria. Patrimonio cultural en la nueva ruralidad andaluza, PH cuadernos, p. 191-217, 2010.

SIDERSKY, P. R., JALFIM, F. T. e ARAÚJO, E. R. A estratégia de assessoria técnica do Projeto Dom Helder Camara. 2. ed. Recife, PE: Projeto Dom Helder Camara, 2010.

SILIPRANDI, E. A reconstrução da extensão rural pública no Brasil: para que, para quem, como? Grupo de trabalho, IX Congresso ALASRU, 2005. Disponível em: $<$ http://www.alasru.org/grupo-de-trabajo-15-quito>. Acesso em: 30 jan. 2015.

SILVA, R. M. A. Entre o combate à seca e a convivência como semi-árido: políticas públicas e transição paradigmática. Tese (Doutorado em Desenvolvimento Sustentável, Politica e Gestão Ambiental) - UnB. Brasília, maio de 2006. Disponível em: <http://www.bnb.gov.br/ projwebren/exec/artigoRenPDF.aspx?cd_artigo ren $=1042$. 20116 $>$. Acesso em: 12, nov. 2013

WANDERLEY, M. de N. B. Agricultura familiar e campesinato: rupturas e continuidade. Estudos Sociedade e Agricultura, n. 21, Rio de Janeiro: out. 2003.

YIN, R. K. Estudo de caso: planejamento e métodos. Porto Alegre: Bookman, 2005. 